\title{
Spinal cord infarction after left lobectomy and continuous thoracic paravertebral block
}

V. Nedkova Hristova, J. Martínez Poles, S. García Madrona, B. Escribano Paredes, A. de Albóniga- Chindurza Barroeta, N. García Barragán, A. Cruz Culebra, R. Vera Lechuga.

Ramón y Cajal Hospital. Madrid.

\section{INTRODUCTION}

Continuous thoracic paravertebral block (PVB) is commonly used and has a low incidence of complications. We report a spinal cord infarction after left lobectomy with video-assisted thoracoscopic surgery (VATS) and PVB following surgery.

\section{MATERIAL AND METHODS}

A 61-year-old woman, with personal history of smoking and pulmonary emphysema, underwent a VATS for solitary pulmonary nodule removal. Thoracic PVB was placed during surgery and kept in the postoperative period.

Some hours later paraparesia was evidenced and the catheter was withdrawn.

Twenty four hours later, the patient had a T3 thermoalgesic level, lower limb apalesthesia, paraparesia (muscle balance on left leg $2 / 5$ proximal and $1 / 5$ distal, on right leg $4 / 5$ proximal and $3 / 5$ distal) and hyperreflexia with left clonus and left Babinski sign.

\section{RESULTS}

- Acute spinal infarction T2-T10 was evidenced in the magnetic resonance of the thoracic spinal cord (figure 1 and figure 2).

- The computed tomography angiography of aorta and supraaortic trunks was normal.

\section{CONCLUSIONS}

If neurological symptoms appear after PVB placement, complications at the spinal cord should be suspected, and spinal cord infarction should be considered in differential diagnosis.

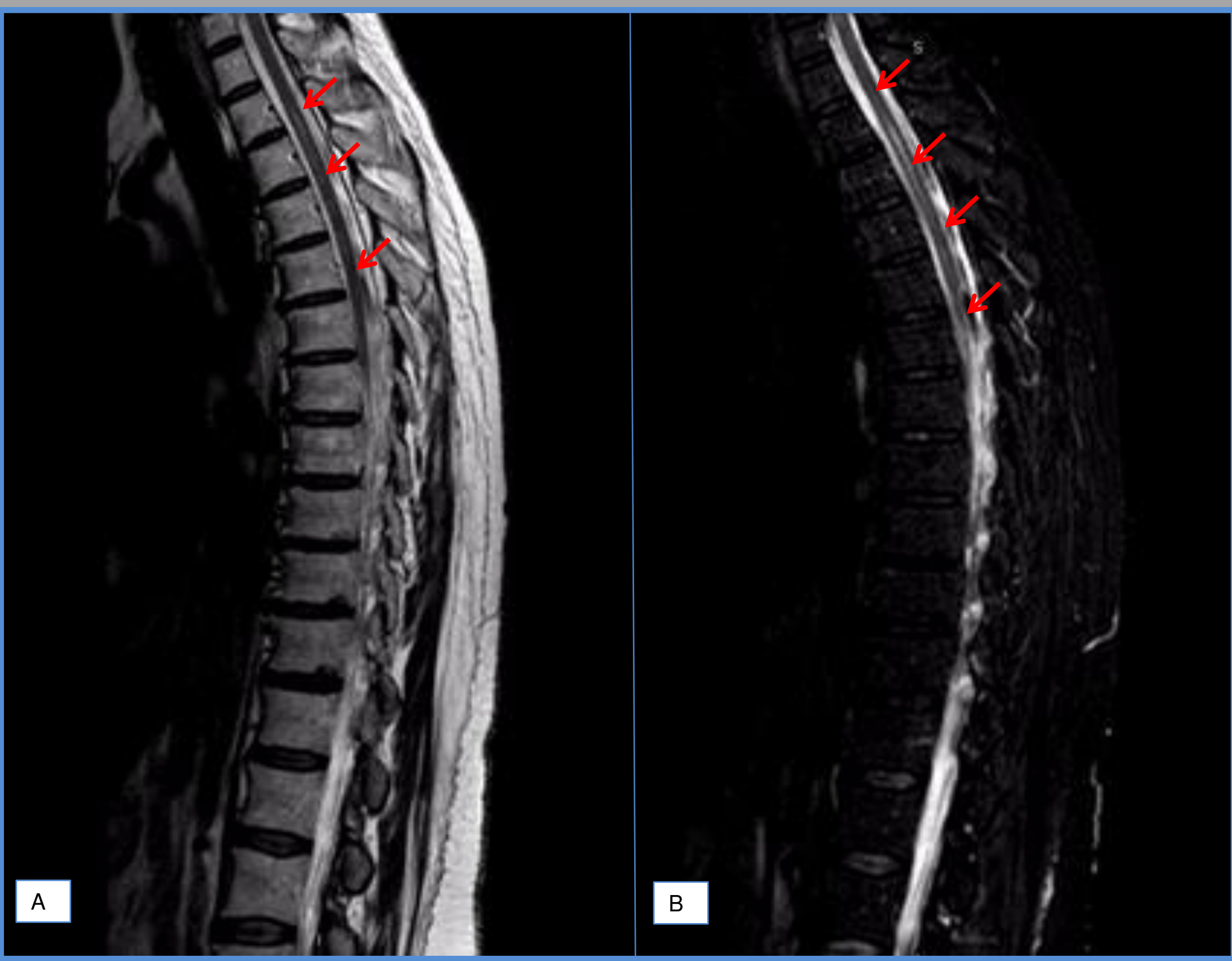

Figure 1. Hyperintense lesion on sagital T2-weighted images $(A)$ and SPIR weighted images (B) in acute spinal cord infarction.

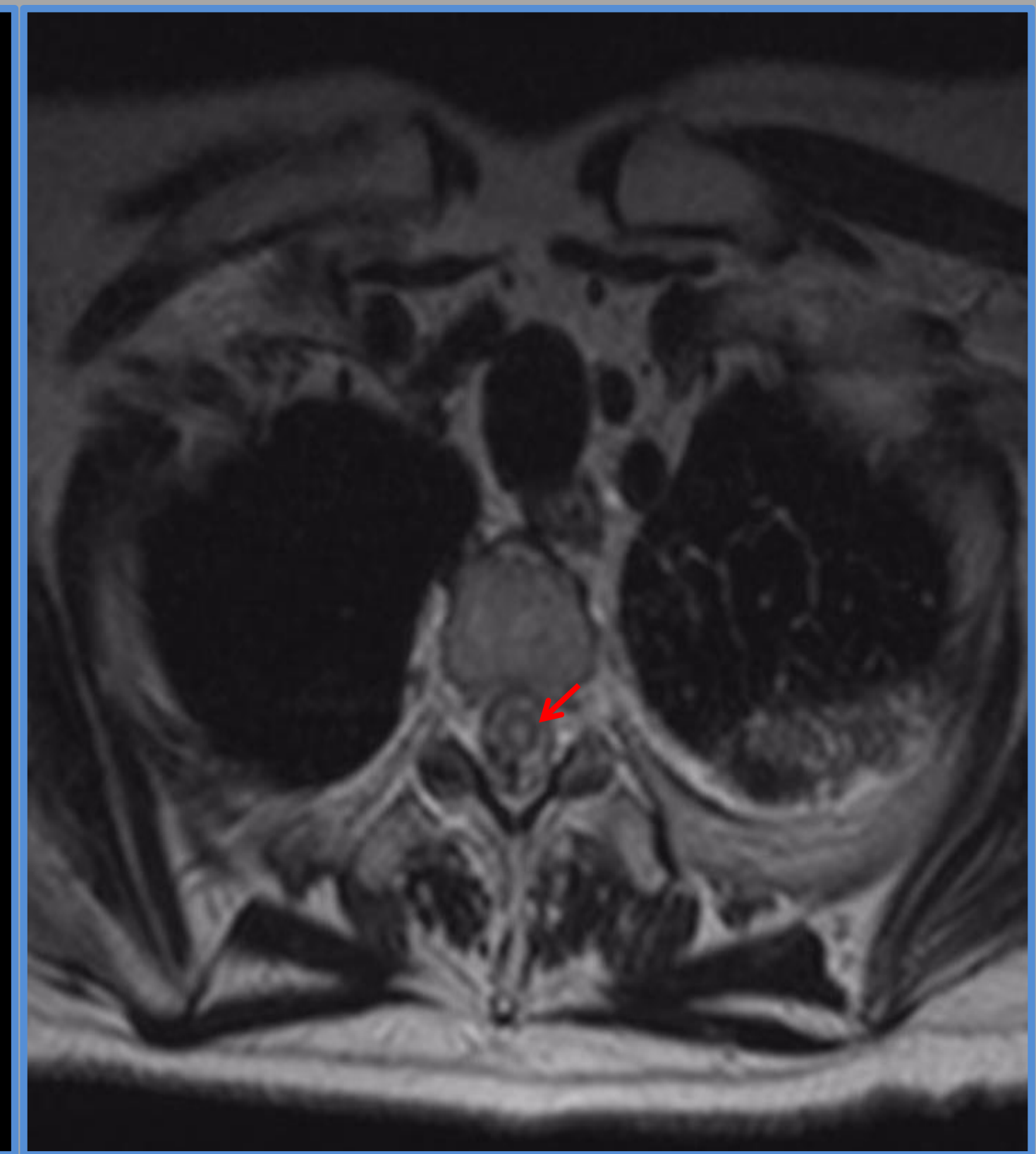

Figure 2. Hyperintense lesion on axial T2weighted images in acute spinal cord infarction.

\section{REFERENCE}

- Batra RK, Krishnan K, Agarwal A. Paravertebral Block. J Anaesthesiol Clin Pharmacol 2011; 27: 5-11.

- Karmakar MK. Thoracic Paravertebral Block. Anesthesiology 2001; 95:771-80. 